\begin{tabular}{|c|l|}
\hline Title & Megaquake cycle at the Tohoku subduction zone with thermal fluid pressurization near the surface \\
\hline Author(s) & Mitsui, Yuta; Kato, Naoyuki; Fukahata, Yukitoshi; Hirahara, Kazuro \\
\hline Citation & $\begin{array}{l}\text { Earth and Planetary Science Letters, 325-326, 21-26 } \\
\text { https://doi.org/40.1016/.epsl.2012.01.026 }\end{array}$ \\
\hline Issue Date & 2012-04_01 \\
\hline Doc URL & http://hdl.handle.net/2115/49213 \\
\hline Type & article(author version) \\
\hline File Information & EPSL325-326_21-26.pdf \\
\hline
\end{tabular}

Instructions for use 


\title{
Megaquake cycle at the Tohoku subduction zone with thermal fluid pressurization near the surface
}

\author{
Yuta Mitsui ${ }^{\mathrm{a}, *}$, Naoyuki Kato ${ }^{\mathrm{b}}$, Yukitoshi Fukahata ${ }^{\mathrm{c}}$, Kazuro Hirahara ${ }^{\mathrm{d}}$ \\ ${ }^{a}$ Department of Natural History Sciences, Hokkaido University, JAPAN \\ ${ }^{b}$ Earthquake Research Institute, University of Tokyo, JAPAN \\ ${ }^{c}$ Disaster Prevention Research Institute, Kyoto University, JAPAN \\ ${ }^{d}$ Department of Geophysics, Kyoto University, JAPAN
}

\begin{abstract}
For the 2011 Tohoku earthquake, we propose a mechanical model to explain rare giant (M9-class) and frequent large (M7-class) earthquakes on a thrust fault in the subduction zone. Observations implied, in the M9 Tohoku earthquake, that extremely large slip on the order of tens of meters occurs in a shallower part to release a slip deficit, as well as substantial slip about ten meters or so in a deeper part including the source area of the M7-class earthquakes. Here, we present a model in which the extremely large slip is caused by hydrothermal weakening (dynamic thermal pressurization of pore fluid) on the fault plane, not by contrast of frictional properties in terms of rate- and statedependent friction. The model explains that the Tohoku earthquake followed a M7-class earthquake in two days, but M7-class earthquakes are not always followed by a giant earthquake. In a giant event, large coseismic slip can occur over an area where quasistatic slip, namely, afterslip of M7-class earthquakes or spontaneous slow slip events, takes place. Slight differences of stress state in the shallow part can result in drastically different coseismic slip. We further perform numerical experiments varying hydraulic parameters and the length of effective hydrothermal weakening area. The experiments imply that observations for monitoring the effective hydrothermal weakening area need spatial resolution on the order of $10 \mathrm{~km}$ or finer.
\end{abstract}

Keywords: giant and large earthquakes, thermal fluid pressurization, thrust fault, 2011 Tohoku earthquake

\section{Introduction}

A giant earthquake off the Pacific coast of Tohoku occurred along the subduction plate boundary off northeastern Japan on March 11, 2011. Its moment magnitude was estimated to be as large as Mw9.0, and its rupture process has been studied by many researchers. Although imaging of the coseismic slip distribution strongly depends on inversion methods, the estimated largest slip near the Japan trench (Ide et al., 2011; Lay et al., 2011; Yagi and Fukahata, 2011) is highly reliable because of inversion analyses of tsunami generation (e.g., Fujii et al. (2011)) and the large displacement detected by GPS/acoustic combination measurements (Sato et al., 2011) and ocean-bottom pressure gauges (Ito et al., 2011) above the fault area. This characteristic seems different from the other M9-class earth-

\footnotetext{
${ }^{*}$ Corresponding author. Mitsui)
}

quakes such as the 1960 Chilean and the 2004 SumatraAndaman earthquakes (Yomogida et al., 2011).

Whether a cycle of M9 earthquakes exists in Tohoku has yet to be determined. Coseismic slip of the Tohoku earthquake over the regions off MiyagiFukushima-Ibaraki has never been observed by geophysical instruments before the 2011 M9 earthquake, although many M7-class earthquakes occurred off Miyagi near the hypocentre of the M9 Tohoku earthquake and at greater depth (Yamanaka and Kikuchi, 2004). However, several studies of tsunami deposits have implied that there were giant earthquakes causing massive tsunamis off Tohoku in the ninth century and another possible later one (Minoura et al., 2001; Sawai et al., 2008).

Based on this situation, the rare phenomenon of the shallow earthquakes with the tsunamis can be related to a rare M9 earthquake. Using a simple system of connected springs and sliders, one study (Mitsui and Iio, 2011) showed that extremely large slip within a limited area caused coseismic slip over the whole fault through 
a conditionally stable area. Another study (Kato and Yoshida, 2011) proposed a possible model for multiple recurrences of rare giant (M9-class) and frequent large (M7-class) earthquakes, assuming a "shallow strong patch". The authors set a two-dimensional fault system to model the region off Miyagi. Friction evolution on the low-dip-angle fault is controlled by rate- and state-dependent friction law (Ruina, 1983) with heterogeneous distribution of parameters. They succeeded in simulating certain phenomena observed in the 2011 Tohoku earthquake: large coseismic slip in a shallower part and interseismic accumulation of slip deficit in comparison with the plate convergence rate in a deeper part including the source areas of the M7-class repeating earthquakes (Yamanaka and Kikuchi, 2004).

However, the existence of such a very strong area in the shallow part has not yet been confirmed by observations. We can raise another possibility. Dynamically low friction caused by thermal pressurization (TP) of pore fluid resulting from shear heating (Sibson, 1973; Bizzarri and Cocco, 2006) in the shallow part causes seismic behaviour similar to that of a shallow strong patch, i.e., long recurrence intervals of earthquakes via large coseismic stress drop (Mitsui and Hirahara, 2009; Noda and Lapusta, 2010). Here we show that introduction of the TP mechanism is appropriate to modelling of the Tohoku earthquake.

\section{Numerical model and methods}

A schematic model of the subduction plate interface off Miyagi is presented in Fig. 1. To model the subducting fault, we use a two-dimensional elastic system (Kato and Hirasawa, 1997). The line fault extends from the ground surface at an angle $20^{\circ}$, driven at a constant plate

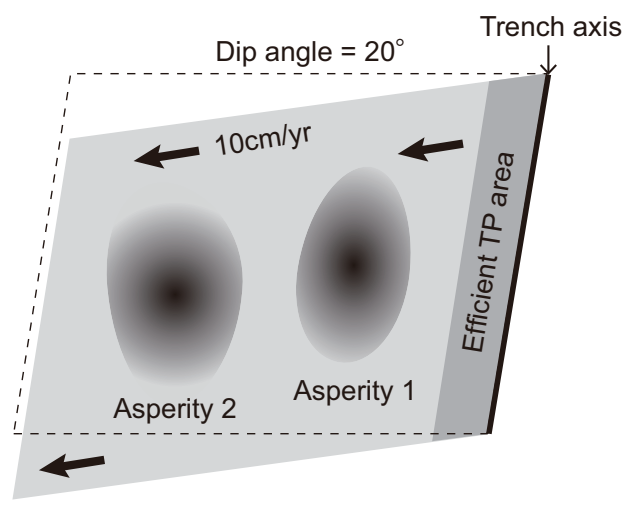

Figure 1: A schematic model of the subduction plate interface off Miyagi. The thermal pressurization effect works in a shallow part (shadow), independent of asperities. convergence rate $v_{p l}=10 \mathrm{~cm} /$ year, and is divided into equal-sized cells. Elastostatic interaction between the cells with $S$-wave radiation damping is assumed (Rice, 1993), using a Green's function in a homogeneous elastic half-space. We set constant values of $37.8 \mathrm{GPa}$ for the rigidity and $3700 \mathrm{~m} / \mathrm{s}$ for the $S$-wave velocity.

The frictional shear stress $\tau^{f}$ at each cell is equal to $\mu(\sigma-p)$, where $\mu$ is the sliding friction coefficient, $\sigma$ is the lithostatic normal stress and $p$ is the pore fluid pressure. The friction coefficient $\mu$ evolves following the rate- and state-dependent friction law with the aging type of the state evolution law (Rice et al., 2001); $\mu$ depends on the slip rate $v$ and the state variable $\theta$ as follows:

$$
\begin{array}{r}
\mu=\mu_{0}+a \ln \left(\frac{v}{v_{0}}\right)+b \ln \left(\frac{v_{0} \theta}{L}\right) \\
\frac{d \theta}{d t}=1-\frac{v \theta}{L}
\end{array}
$$

where $\mu_{0}$ is a reference frictional coefficient 0.6 , and $v_{0}$ is a reference slip rate equal to the plate convergence rate $v_{p l} . a, b$, and $L$ are the constitutive parameters. Positive $a-b$ represents a velocity-strengthening character of steady-state friction, and negative $a-b$ represents a velocity-weakening character. A large value of $(b-a) / L$ favors stick-slip behaviour (Ruina, 1983).

We assume rheological parameter distributions imaging the subduction plate interface off Miyagi: M7-class earthquakes occurred at greater depth in 1978 and 2005 and at shallower depth in 1981 and 2011 before the Tohoku earthquake. We follow the parameter distributions for the rate and state friction, $a, b$, and $L$, in a previous study (Kato and Yoshida, 2011) except near the free surface. The parameter distributions of $a_{n}=a\left(\sigma-p_{0}\right)$ and $b_{n}=b\left(\sigma-p_{0}\right)$, where $p_{0}$ is a basal value of the pore pressure $p$ less than the lithostatic normal stress $\sigma$, are illustrated in Fig. 2. The parameter distributions are also described in Table 1.

The basal effective normal stress $\sigma-p_{0}$ is assumed to be low owing to fluid overpressurization (Rice, 1992), being 44.1 MPa at all cells deeper than $2.2 \mathrm{~km}$. Such weakness of the plate interface along the Japan trench was estimated based on heat-flow data (Furukawa and Ueda, 1989) and force balance in the forearc (Seno, 2009). In the shallowest part, $\sigma-p_{0}$ is given by (20 MPa $\left.\mathrm{km}^{-1}\right) \times($ depth in $\mathrm{km})$. These distributions make two asperities with the velocity-weakening character. We call the shallower asperity around a depth of $30 \mathrm{~km}$ Asperity 1 , and we call the deeper asperity around a depth of $50 \mathrm{~km}$ Asperity 2. We set a velocity-strengthening patch between the two asperities, reflecting the existence of a region without coseismic slip in M7-class 


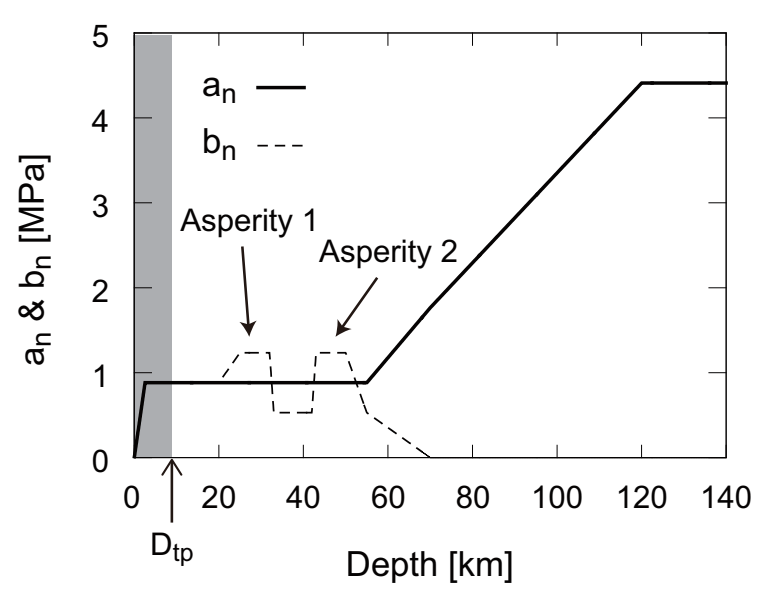

Figure 2: Parameter distributions of $a_{n}=a\left(\sigma-p_{0}\right)$ and $b_{n}=b(\sigma-$ $\left.p_{0}\right)$ along the subducting plate interface. The details are described in Table 1. From the free surface to a depth of $D_{t p} \mathrm{~km}$, the thermal pressurization mechanism works effectively.

earthquakes (Yamanaka and Kikuchi, 2004; Miura et al., 2006). In the area shallower than Asperity 1, a velocityneutral friction $a_{n}=b_{n}$ is assumed since we do not have sufficient information about the near-trench plate coupling. We set a constant $L$ of $0.05 \mathrm{~m}$ over the whole fault.

The pore pressure $p$ increases by thermal pressurization only in the shallow area, referred to as the TP area, from the free surface to a depth $D_{t p}$. In the deeper part, the pore pressure remains constant during whole earthquake cycles.

In our TP model, the fluid-infiltrated fault is subject to homogeneous one-dimensional shear with frictional heating within finite thickness $w$ (Cardwell et al., 1978). The pore pressure $p$ evolves via frictional heating, heat flow, and fluid flow, i.e., the law of energy conservation, the Fourier law, the law of mass conservation, and the Darcy law. The fluid and heat flows are assumed to be one-dimensional and perpendicular to the fault. Without a discrete assumption for the diffusions (Segall and Rice, 2006), the pore pressure $p$ at time $t$ on the centre of the fault (Bizzarri and Cocco, 2006; Mitsui and Hirahara, 2009; Bizzarri, 2010; Mitsui and Cocco, 2010) is given by

$$
\begin{array}{r}
p(t)=p_{0}+\frac{A}{w} \int_{0}^{t} d t^{\prime}\left[-\frac{\chi}{\varpi-\chi} \operatorname{erf}\left(\frac{w}{4 \sqrt{\chi\left(t-t^{\prime}\right)}}\right)\right. \\
\left.+\frac{\varpi}{\varpi-\chi} \operatorname{erf}\left(\frac{w}{4 \sqrt{\varpi\left(t-t^{\prime}\right)}}\right)\right]
\end{array}
$$

$$
\left.\cdot(\mu(\sigma-p) v)\right|_{t^{\prime}}
$$

where $\chi$ is the temperature diffusivity, $\varpi$ is the diffusivity of pore pressure, and $A$ is the non-dimensional material parameter containing the fluid thermal expansivity, the fluid pressure compressibility, the bulk density, and the bulk specific heat. We assume $w=0.02 \mathrm{~m}$, $A=0.18$, and $\chi=1.1 \times 10^{-6} \mathrm{~m}^{2} / \mathrm{s}$, as typical values for underground rocks (Wibberley and Shimamoto, 2003; Noda and Shimamoto, 2005).

The size of the numerically divided cells must be smaller than certain critical sizes within the framework of the continuum limit (Rice, 1993). In particular, for an aging type of state evolution law without pore pressure evolution, the cell size must be smaller than $G L /\left(b_{n}-a_{n}\right)$. For the distribution of the parameters shown in Fig. 2, the least value of the critical length $G L /\left(b_{n}-a_{n}\right)$ is approximately $107000 L$. In this study, we set the cell size equal to $200 \mathrm{~m}$. It is one or more orders of magnitude smaller than the critical length.

As initial values, we assume steady-state conditions at all cells: $v=0.9 v_{0}, \theta=L /\left(0.9 v_{0}\right), p=p_{0}$, and $\tau=\tau^{0}$. To solve the equation system, we first use the RK45 algorithm (Press et al., 1992) with adaptive stepsize control to obtain the evolution of $\tau, \theta$, and $v$ by solving the ordinary differential system of $d \tau / d t, d \theta / d t$, and $d v / d t$. The constitutive equations allow us to obtain a tentative value of $p$. Then, all of the variables are recalculated using a fourth-order Runge-Kutta method. When the slip rate $v$ does not exceed $v_{0}$, the memory of the shear heating term is not stored (Mitsui and Hirahara, 2009).

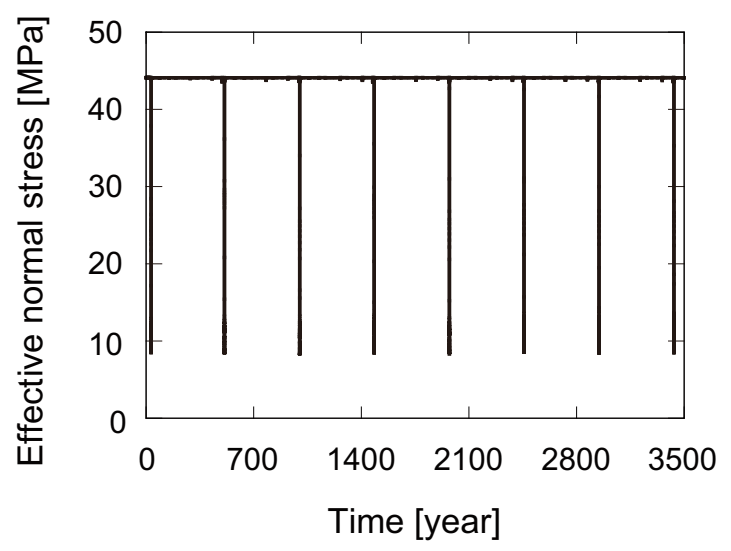

Figure 3: Evolution of the effective normal stress $\sigma-p$ at a depth of 5 $\mathrm{km}$, when we set $\varpi=10^{-2} \mathrm{~m}^{2} / \mathrm{s}$ and $D_{t p}=10 \mathrm{~km}$. The giant events marked by the lowest effective normal stress repeat at an interval of 487 years. 

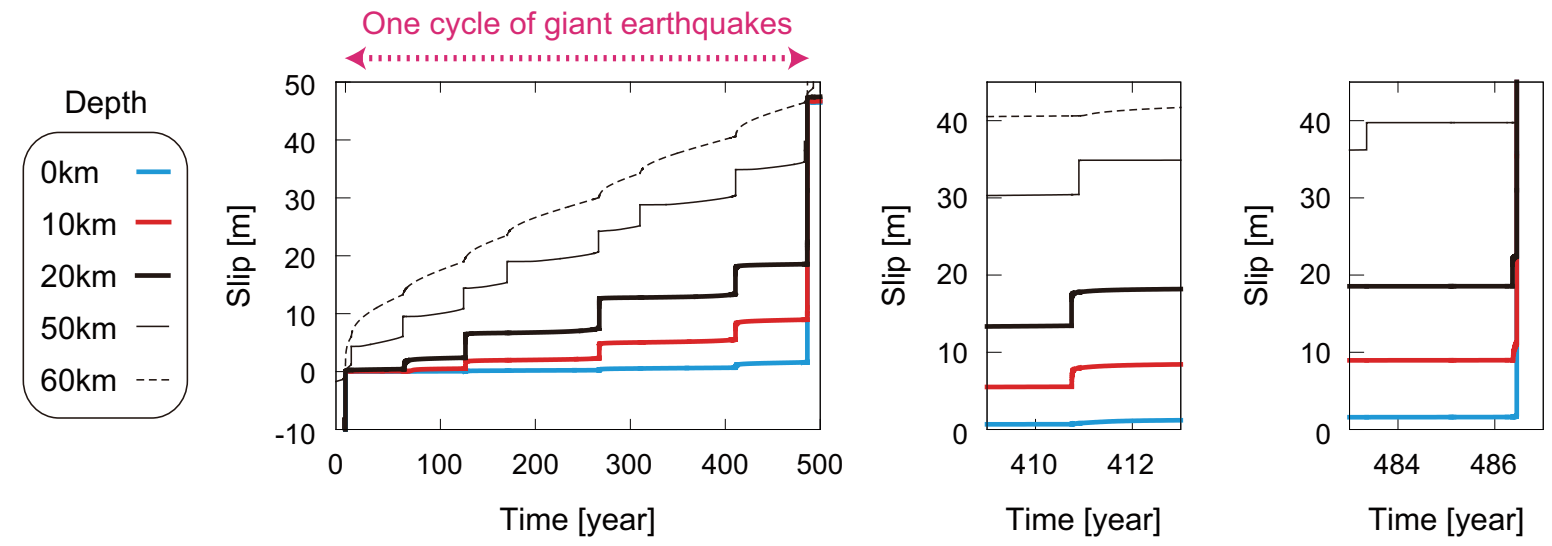

Figure 4: Evolution of the slip during one cycle of a giant event at several depths, when we set $\varpi=10^{-2} \mathrm{~m}^{2} / \mathrm{s}$ and $D_{t p}=10 \mathrm{~km}$. Depths of 0 and $10 \mathrm{~km}$ are both in the TP area, $20 \mathrm{~km}$ is at the upper edge of Asperity 1, $50 \mathrm{~km}$ is in Asperity 2, and $60 \mathrm{~km}$ is in the deeper area.

\section{Results}

We perform a set of model calculations for the thermal pressurization effect by varying two parameters: the hydraulic diffusivity $\varpi$ and the depth limit for the thermal pressurization effect $D_{t p}$. In particular, we examine three cases for the pore pressure diffusivity $\varpi$ in the TP area: $\varpi=10^{-2} \mathrm{~m}^{2} / \mathrm{s}, 10^{-3} \mathrm{~m}^{2} / \mathrm{s}$, and $10^{-4} \mathrm{~m}^{2} / \mathrm{s}$, with $D_{t p}$ varying in the range of $4-12 \mathrm{~km}$. The system behaves as a limit cycle for the giant events, after the disappearance of the effect of the initial condition.

First, we show an example of the results, when we set $\varpi=10^{-2} \mathrm{~m}^{2} / \mathrm{s}$ and $D_{t p}=10 \mathrm{~km}$. Fig. 3 presents the evolution of the effective normal stress $\sigma-p$ at a depth of $5 \mathrm{~km}$. After the disappearance of the effect of the initial condition, giant events with the lowest effective normal stress, which means the most intense fluid pressurization during coseismic slip, repeat at an interval of 487 years. The pore pressure also increases very slightly for smaller events.

For the same case, the slip evolution during one cycle of giant events is shown in Fig. 4, at several depths. Depths of 0 and $10 \mathrm{~km}$ are in the TP area, $20 \mathrm{~km}$ is at the upper edge of Asperity 1, $50 \mathrm{~km}$ is in Asperity 2, and $60 \mathrm{~km}$ is in the deeper area.

Several key points can be made:

1. Giant coseismic slips, including earthquakes at Asperities 1 and 2, repeat themselves.

2. Earthquakes at Asperities 1 and 2 do not fully release the slip deficit expected from the plate convergence rate, which is released by a giant earthquake.

3. A giant earthquake immediately follows an earthquake at Asperity 1 (Fig. 4), but an earthquake at
Asperity 1 is not always followed by a giant earthquake.

Points 1 and 2 are the same as presented in a previous study (Kato and Yoshida, 2011) but point 3 is different, since the TP area with the largest coseismic slip in this study is not frictionally unstable to nucleate spontaneously (i.e., $a_{n}-b_{n}$ not negative). In the study (Kato and Yoshida, 2011), the largest slip is assumed to occur at the strong patch, most of which is locked during interseismic periods of the giant earthquakes. By contrast, our model does not have this characteristic. For example, Fig. 4 shows that even the cell at a depth

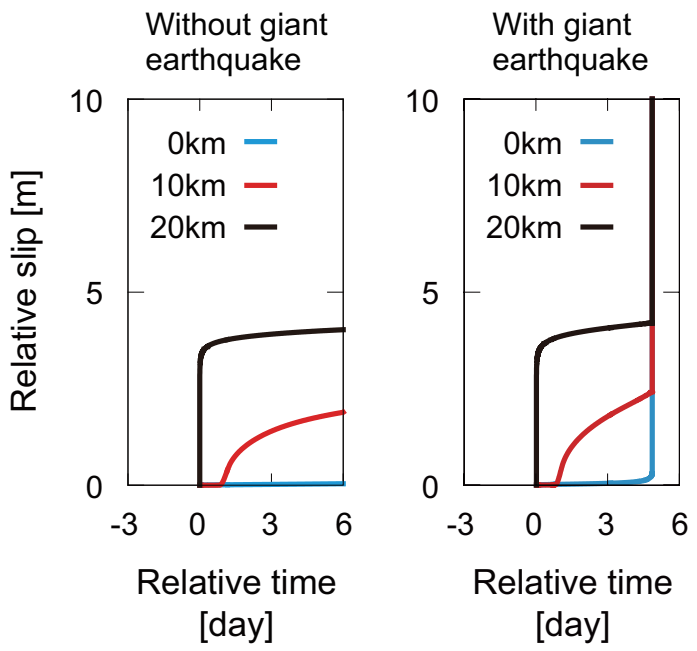

Figure 5: Temporal evolution of the slip around an earthquake at Asperity 1 , without and with a following giant earthquake, for $\varpi=10^{-2}$ $\mathrm{m}^{2} / \mathrm{s}$ and $D_{t p}=12 \mathrm{~km}$. Time and slip are measured from the occurrence of an earthquake at Asperity 1. Depths of 0 and $10 \mathrm{~km}$ are both in the TP area, and $20 \mathrm{~km}$ is at the upper edge of Asperity 1. 
of $0 \mathrm{~km}$ can slip aseismically, in particular as afterslip of the earthquakes at Asperity 1. If we assume negative but small $\left|a_{n}-b_{n}\right|$ (weak character of the velocityweakening) in the TP area, slow-slip events would occur during interseismic periods of the giant earthquakes. Because TP is a strongly nonlinear effect of positive feedback for fault weakening, it can notably affect the nucleation process (Segall and Rice, 2006). Our results show that the nonlinear effect of TP enhances the nucleation of slip instability triggered by stress perturbations.

In the parameter ranges we examine, the time lags between an earthquake at Asperity 1 and the following giant earthquake are from several hours to several days. In Fig. 5, we compare the slip evolution around an earthquake at Asperity 1 that is, respectively, not followed or followed by a giant earthquake. These simulated slip histories look similar, but they are slightly different in the amounts of afterslip. The large and slowly decaying afterslip is due to higher shear stress in the TP area. For example, in the cases of Fig. 5, five days after the event at Asperity 1, the shear stress values at a depth of 10 $\mathrm{km}$ differ by the order of $100 \mathrm{kPa}$. The larger afterslip resulting from stress accumulation in the TP area may be a sign of the following giant earthquake; of course we must distinguish between the sign, for example, implied by a GPS data inversion study (Suito et al., 2011), and "ordinary" large afterslip (Heki et al., 1997) as a regional characteristic.

\section{Discussion}

\subsection{Effect of hydraulic parameters on stress drop and recurrence interval}

Fig. 6 shows the recurrence intervals of giant earthquakes for different parameters $\varpi$. Smaller $\varpi$ leads to longer recurrence intervals because of larger stress drop owing to smaller friction during coseismic slip (Mitsui and Hirahara, 2009). Larger $D_{t p}$ also causes longer recurrence intervals owing to an increase of the area with large stress drop by TP. Fluctuations of the hydraulic condition in actual faults (Sibson, 1992) can cause notable change of the recurrence intervals of giant earthquakes. These may correspond to large fluctuations of the recurrence intervals of the giant earthquakes estimated from tsunami deposits (Sawai et al., 2008).

To check the effect of stress drop on the recurrence interval, we measure the mean stress drop within the "TP area" (depth $\left.<D_{t p}\right)$ and the "seismogenic area" (defined as depth $<55 \mathrm{~km}$, including Asperities 1 and 2 from the free surface), where we approximate the stress drop at each cell by a difference between $\tau^{0}=\mu_{0}\left(\sigma-p_{0}\right)$

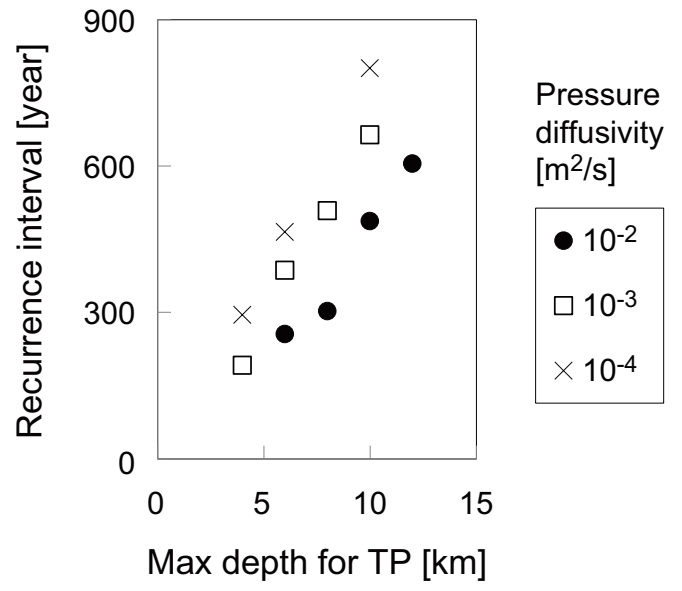

Figure 6: Calculated recurrence intervals of giant earthquakes for different $\varpi$ in the thermal pressurization area $\left(\varpi=10^{-2} \mathrm{~m}^{2} / \mathrm{s}, 10^{-3}\right.$ $\mathrm{m}^{2} / \mathrm{s}$, and $10^{-4} \mathrm{~m}^{2} / \mathrm{s}$ ) with $D_{t p}$ varying in the range of $4-12 \mathrm{~km}$.

and the minimal shear stress. Since $\tau^{0}$ below a depth of $2.2 \mathrm{~km}$ is $0.6 \times 44.1 \simeq 26 \mathrm{MPa}$, the stress drop at each cell does not exceed $26 \mathrm{MPa}$. We plot the mean stress drop for the recurrence interval in Fig. 7. The recurrence interval of giant earthquakes strongly depends on the value of the stress drop. In particular, the recurrence interval over 600 years, which may be adequate for the Tohoku earthquake, is characterized by a mean stress drop of over $6 \mathrm{MPa}$ within the seismogenic area and over $20 \mathrm{MPa}$ within the TP area. It is also characterized by $D_{t p}>10 \mathrm{~km}$, namely the length of the TP area $>30 \mathrm{~km}$ along the fault. This fact implies that observations for monitoring the near-trench TP area should

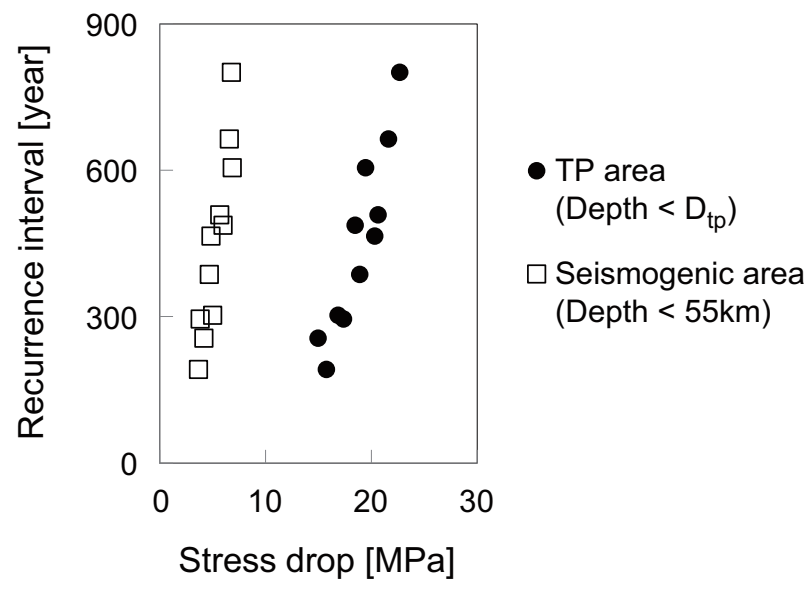

Figure 7: Calculated recurrence intervals of giant earthquakes for the mean values of the stress drop in the TP area (depth $<D_{t p}$ from the free surface) and the seismogenic area (depth $<55 \mathrm{~km}$ from the free surface). 
have spatial resolution on the order of $10 \mathrm{~km}$ or finer.

The low residual stress after the giant earthquake near the trench in our model corresponds to frequent occurrences of normal-fault-type aftershocks of the 2011 Tohoku earthquake. More quantitatively, a nearly complete stress drop in the source region of the 2011 Tohoku earthquake was proposed (Hasegawa et al., 2011) using a stress-tensor inversion method. Stress drop values were also investigated by a slip inversion study (Yagi and Fukahata, 2011). They estimated typical stress drop values of about $20 \mathrm{MPa}$ near the trench and 0-10 $\mathrm{MPa}$ in the down-dip source area. Their estimated values are almost consistent with our results (Fig. 7), although our definition of stress drop is not identical to theirs.

\subsection{Validity of the shallow TP area hypothesis}

We assume that the TP area is near the free surface, and causes unusual stress drop with large slip in the shallow part and propagation of seismic slip to the deeper part. Here, we consider the validity of the assumption that TP works only in the very shallow area.

For effective TP, both of sufficiently strong shear heating and small hydraulic diffusivity are necessary (Bizzarri and Cocco, 2006). Indeed, in the Chi-Chi earthquake of 1999, TP effectively worked near the Earth's surface in the northern fault zone (Tanikawa and Shimamoto, 2009). Furthermore, at the Nobeoka thrust fault, Japan, evidence of dynamic changes of fluid state caused by temperature changes was reported ( $\mathrm{Ya}$ maguchi et al., 2011). Thus effective TP in a shallow part is not a peculiar assumption for the 2011 Tohoku earthquake fault.

However, there is little evidence to support the assumption of the absence of TP at greater depth because of the lack of information about underground fault conditions. One possible explanation is the counteraction of pore dilatation to the pore pressure increase by TP (Suzuki and Yamashita, 2007). The pore dilatation increases effective normal stress $\sigma-p$ during slip acceleration phases. The dilatancy itself leads to higher rate of heating production. In contrast, the dilatancy has a fault stabilizing effect to brake slip acceleration (Rudnicki and Chen, 1988), leading to lower rate of heating production. Thus the role of pore dilatation in frictional instabilities depends on circumstances. In particular, one study (Mitsui and Cocco, 2010) proposed that the latter restraining effect of porosity evolution on thermal pressurization is stronger in more impermeable cases (i.e., larger $w / w_{h y}$, where $w$ is the slip zone thickness and $w_{h y}$ is the characteristic length of fluid diffusion (Mitsui and Cocco, 2010)). Since the weak fault assumption (low $\sigma-p_{0}$ ) is based on low permeability in a deeper part (Rice, 1992), that implication by Mitsui and Cocco (2010) can explain the absence of effective $\mathrm{TP}$ at greater depth.

\subsection{Comparison with observations}

Before the occurrence of the 2011 Tohoku earthquake, seismic slip of M7-class earthquakes off Miyagi did not fully release the slip deficit expected from the plate convergence rate (Yamanaka and Kikuchi, 2004; Kanamori et al., 2006). Several geodetical studies using GPS data also revealed the same tendency (Ito et al., 2000; Nishimura et al., 2004; Suwa et al., 2006). These studies all mentioned the noticeable slip deficit, in the deeper part. However, in the shallow part near the trench, there was little information. Since the neartrench slip and plate coupling are poorly constrained by on-land GPS (Loveless and Meade, 2011), observations of ocean-bottom deformation are definitely important.

If our model is appropriate to model the subduction zone, giant earthquakes could occur without a shallow strong patch (Kato and Yoshida, 2011) with higher effective normal stress and a large value of characteristic slip distance $L$. A giant earthquake is likely to preceded by a rather pronounced afterslip than previous ones at the same place. Our study further implies that oceanbottom observations should be sufficiently dense (on the order of $10 \mathrm{~km}$ or finer) to monitor the plate interface.

\section{Conclusions}

We showed that quasistatic slip events near a trench can grow to extremely large seismic slip by TP, once the stress state in the TP area is prepared. Even a slight difference in shear stress on the order of $100 \mathrm{kPa}$ can cause entirely dissimilar results, owing to the strongly nonlinear effect of TP. This explains why the M7.3 event at Asperity 1 on March 9, 2011, was followed by the 2011 Tohoku earthquake on March 11, but the M7.1 event at Asperity 1 in 1981, was not followed by a giant earthquake (Fig. 4). The propagation velocity and slip velocity of afterslip in the TP area depend on the stress field, and they can be greater than those in ordinary afterslip.

We further performed numerical experiments varying the hydraulic parameters and the length of the TP area. The experiments implied that observations for monitoring the plate interface around the near-trench TP area need spatial resolution on the order of $10 \mathrm{~km}$ or finer. In addition, temporal fluctuations of the hydraulic condition may possibly explain the fluctuations of the recurrence intervals of the giant earthquakes. 


\section{Acknowledgments}

We thank Y. Iio and T. Matsuzawa for valuable discussions and comments. We would also like to thank two anonymous reviewers. Y.M. is supported by a JSPS fellowship provided by the Japan Society for the Promotion of Science. This research is supported by the MEXT (Ministry of Education Culture and Sports and Technology of Japan) project "New research project for the evaluation of seismic linkage around the Nankai trough".

\section{References}

Bizzarri, A. (2010), On the recurrence of earthquakes: Role of wear in brittle faulting, Geophys. Res. Lett., 37(L20315), doi: 10.1029/2010GL045480.

Bizzarri, A., and M. Cocco (2006), A thermal pressurization model for the spontaneous dynamic rupture propagation on a threedimensional fault: 1. Methodological approach, J. Geophys. Res., 111(B05303), doi:10.1029/2005JB003862.

Cardwell, R. K., D. S. Chinn, G. F. Moore, and D. L. Turcotte (1978), Frictional heating on a fault zone with finite thickness, Geophys. $J$. R. Astr. Soc., 52, 525-530.

Fujii, Y., K. Satake, S. Sakai, M. Shinohara, and T. Kanazawa (2011), Tsunami source of the 2011 off the Pacific coast of Tohoku, Japan earthquake, Earth Planets Space, 63, 815-820.

Furukawa, Y., and S. Ueda (1989), Thermal state under the Tohoko arc with consideration of crustal heat generation, Tectonophysics, 164, 175-187, doi:10.1016/0040-1951(89)90011-5.

Hasegawa, A., K. Yoshida, and T. Okada (2011), Nearly complete stress drop in the 2011 Mw9.0 off the Pacific coast of Tohoku Earthquake, Earth Planets Space, 63, 703-707.

Heki, K., S. Miyazaki, and H. Tsuji (1997), Silent fault slip following an interplate thrust earthquake at the Japan Trench, Nature, 386, 595-598, doi:10.1038/386595a0.

Ide, S., A. Baltay, and G. C. Beroza (2011), Shallow Dynamic Overshoot and Energetic Deep Rupture in the $2011 \mathrm{Mw}$ 9.0 Tohoku-Oki Earthquake, Science, 332, 1426-1429, doi: 10.1126/science.1207020.

Ito, T., S. Yoshioka, and S. Miyazaki (2000), Interplate coupling in northeast Japan deduced from inversion analysis of GPS data, Earth Planet. Sci. Lett., 176, 117-130, doi:10.1016/S0012821X(99)00316-7.

Ito, Y., T. Tsuji, Y. Osada, M. Kido, D. Inazu, Y. Hayashi, H. Tsushima, R. Hino, and H. Fujimoto (2011), Frontal wedge deformation near the source region of the 2011 Tohoku-Oki earthquake, Geophys. Res. Lett., 38(15), doi:10.1029/2011GL048355.

Kanamori, H., M. Miyazawa, and J. Mori (2006), Investigation of the earthquake sequence off Miyagi prefecture with historical seismograms, Earth Planets Space, 58, 1533-1541.

Kato, N., and T. Hirasawa (1997), A numerical study on seismic coupling along subduction zones using a laboratory-derived friction law, Phys. Earth Planet. Int., 102(1-2), 51-68, doi:10.1016/S00319201(96)03264-5.

Kato, N., and S. Yoshida (2011), A shallow strong patch model for the 2011 great Tohoku-oki earthquake: A numerical simulation, Geophys. Res. Lett., 38(L00G04), doi:10.1029/2011GL048565.

Lay, T., C. J. Ammon, H. Kanamori, L. Xue, and M. J. Kim (2011), Possible large near-trench slip during the great 2011 Tohoku (Mw 9.0) earthquake, Earth Planets Space, 63, 687-692, doi:10.5047/eps.2011.05.033.
Loveless, J. P., and B. J. Meade (2011), Spatial correlation of interseismic coupling and coseismic rupture extent of the $2011 \mathrm{Mw}$ = 9.0 Tohoku-oki earthquake, Geophys. Res. Lett., 38(17), doi: 10.1029/2011GL048561.

Minoura, K., F. Imamura, D. Sugawara, Y. Kono, and T. Iwashita (2001), The 869 Jogan tsunami deposit and recurrence interval of large-scale tsunami on the Pacific coast of northeast Japan, J. Natural Disaster Sci., 23, 83-88.

Mitsui, Y., and M. Cocco (2010), The Role of porosity evolution and fluid flow in frictional instabilities: A parametric study using a spring-slider dynamic system, Geophys. Res. Lett., 37(L23305), doi:10.1029/2010GL045672.

Mitsui, Y., and K. Hirahara (2009), Coseismic thermal pressurization can notably prolong earthquake recurrence intervals on weak rate and state friction faults: Numerical experiments using different constitutive equations, J. Geophys. Res., 114(B09304), doi: 10.1029/2008JB006220.

Mitsui, Y., and Y. Iio (2011), How did the 2011 Off the Pacific Coast of Tohoku Earthquake start and grow? The role of a conditionally stable area, Earth Planets Space, 63, 755-759, doi: 10.5047/eps.2011.05.007.

Miura, S., T. Inuma, S. Yui, N. Uchida, T. Sato, K. Tachibana, and A. Hasegawa (2006), Co- and post-seismic slip associated with the 2005 Miyagi-oki earthquake (M7.2) as inferred from GPS data, Earth Planets Space, 58, 1567-1572.

Nishimura, T., T. Hirasawa, S. Miyazaki, T. Sagiya, T. Tada, S. Miura, and K. Tanaka (2004), Temporal change of interplate coupling in northeastern Japan during 1995-2002 estimated from continuous GPS observations, Geophys. J. Int., 157, 901-916, doi: 10.1111/j.1365-246X.2004.02159.x.

Noda, H., and N. Lapusta (2010), Three-dimensional earthquake sequence simulations with evolving temperature and pore pressure due to shear heating: Effect of heterogeneous hydraulic diffusivity, J. Geophys. Res., 115(B12314), doi:10.1029/2010JB007780.

Noda, H., and T. Shimamoto (2005), Thermal Pressurization and SlipWeakening Distance of a Fault: An Example of the Hanaore Fault, Southwest Japan, Bull. Seis. Soc. Am., 95(4), 1224-1233, doi: 10.1785/0120040089.

Press, W. H., B. P. Teukolsky, and W. T. Vetterling (1992), Numerical Recipes, 2nd ed., Cambridge University Press, New York.

Rice, J., N. Lapusta, and K. Ranjith (2001), Rate and state dependent friction and the stability of sliding between elastically deformable solids, J. Mech. Phys. Solids, 49(9), 1865-1898, doi: 10.1016/S0022-5096(01)00042-4.

Rice, J. R. (1992), Fault stress states, pore pressure distributions, and the weakness of the San Andreas Fault, in Fault Mechanics and Transport Properties in Rocks, pp. 475-503, Academic, New York, doi:10.1016/S0074-6142(08)62835-1.

Rice, J. R. (1993), Spatio-temporal Complexity of Slip on a Fault, J. Geophys. Res., 98(B6), 9885-9907, doi:10.1029/93JB00191.

Rudnicki, J. W., and C.-H. Chen (1988), Stabilization of rapid frictional slip on a weakening fault by dilatant hardening, J. Geophys. Res., 93(B5), 4745-4757.

Ruina, A. (1983), Slip Instability and State Variable Friction Laws, J. Geophys. Res., 88(B12), 10,359-10,370, doi: 10.1029/JB088iB12p10359.

Sato, M., T. Ishikawa, N. Ujihara, S. Yoshida, M. Fujita, M. Mochizuki, and A. Asada (2011), Displacement Above the Hypocenter of the 2011 Tohoku-Oki Earthquake, Science, 332, 1395, doi:10.1126/science.1207401.

Sawai, Y., Y. Fujii, O. Fujiwara, T. Kamataki, J. Komatsubara, Y. Okamura, M. Shishikura, and K. Satake (2008), Marine incursions of the past 1500 years and evidence of tsunamis at Suijin-numa, a coastal lake facing the Japan Trench, The Holocene, 18, 517-528.

Segall, P., and J. R. Rice (2006), Does shear heating of pore fluid con- 
tribute to earthquake nucleation?, J. Geophys. Res., 111(B09316), doi:10.1029/2005JB004129.

Seno, T. (2009), Determination of the pore fluid pressure ratio at seismogenic megathrusts in subduction zones: Implications for strength of asperities and Andean-type mountain building, J. Geophys. Res., 114(B05405), doi:10.1029/2008JB005889.

Sibson, R. (1992), Implications of fault-valve behaviour for rupture nucleation and recurrence, Tectonophysics, 211, 283-293, doi: 10.1016/0040-1951(92)90065-E.

Sibson, R. H. (1973), Interactions between temperature and fluid pressure during earthquake faulting - a mechanism for partial or total stress relief, Nature, 243, 66-68, doi:10.1038/physci243066a0.

Suito, H., T. Nishimura, M. Tobita, T. Imakiire, and S. Ozawa (2011), Interplate fault slip along the Japan Trench before the occurrence of the 2011 off the Pacific coast of Tohoku Earthquake as inferred from GPS data, Earth Planets Space, 63, 615-619.

Suwa, Y., S. Miura, A. Hasegawa, T. Sato, and K. Tachibana (2006), Interplate coupling beneath NE Japan inferred from threedimensional displacement field, J. Geophys. Res., 111(B04402), doi:10.1029/2004JB003203.

Suzuki, T., and T. Yamashita (2007), Understanding of slipweakening and -strengthening in a single framework of modeling and its seismological implications, Geophys. Res. Lett., 34(13), doi:10.1029/2007GL030260.

Tanikawa, W., and T. Shimamoto (2009), Frictional and transport properties of the Chelungpu fault from shallow borehole data and their correlation with seismic behavior during the 1999 Chi-Chi earthquake, J. Geophys. Res., 114(B01402), doi: 10.1029/2008JB005750.

Wibberley, C., and T. Shimamoto (2003), Internal structure and permeability of major strike-slip fault zones: the Median Tectonic Line in Mie Prefecture, Southwest Japan, J. Struct. Geol., 25(1), 59-78, doi:10.1016/S0191-8141(02)00014-7.

Yagi, Y., and Y. Fukahata (2011), Rupture process of the 2011 Tohoku-oki earthquake and absolute elastic strain release, Geophys. Res. Lett., 38(L19307), doi:10.1029/2011GL048701.

Yamaguchi, A., S. F. Cox, G. Kimura, and S. Okamoto (2011), Dynamic changes in fluid redox state associated with episodic fault rupture along a megasplay fault in a subduction zone, Earth Planet. Sci. Lett., 302, 369-377, doi:10.1016/j.epsl.2010.12.029.

Yamanaka, Y., and M. Kikuchi (2004), Asperity map along the subduction zone in northeastern Japan inferred from regional seismic data, J. Geophys. Res., 109(B07307), doi:10.1029/2003JB002683.

Yomogida, K., K. Yoshizawa, J. Koyama, and M. Tsuzuki (2011), Along-dip segmentation of the 2011 off the Pacific coast of Tohoku Earthquake and comparison with other megathrust earthquakes, Earth Planets Space, 63, 697-701. 
Table 1: Detailed parameter distributions of $a_{n}=a\left(\sigma-p_{0}\right)$ and $b_{n}=b\left(\sigma-p_{0}\right)$ along the plate interface.

\begin{tabular}{ccc}
\hline Depth range $[\mathrm{km}]$ & $a_{n}[\mathrm{MPa}]$ & $b_{n}[\mathrm{MPa}]$ \\
\hline $0-2.2$ & $0-0.882$ (linear change) & $0-0.882$ (linear change) \\
$2.2-20$ & 0.882 & 0.882 \\
$20-25$ & 0.882 & $0.882-1.235$ (linear change) \\
$25-32$ & 0.882 & 1.235 \\
$32-33$ & 0.882 & $1.235-0.529$ (linear change) \\
$33-42$ & 0.882 & 0.529 \\
$42-43$ & 0.882 & $0.529-1.235$ (linear change) \\
$43-50$ & 0.882 & 1.235 \\
$50-55$ & 0.882 & $1.235-0.529$ (linear change) \\
$55-70$ & $0.882-1.764$ (linear change) & $0.529-0$ (linear change) \\
$70-120$ & $1.764-4.41$ (linear change) & 0 \\
$120-$ & 4.41 & 0 \\
\hline
\end{tabular}

